\title{
Comparison of Threshold Power between Methylene Blue Degradation and KI Oxidation Reaction Using Ultrasound
}

\author{
Daisuke Kobayashi' ${ }^{1}$ Chiemi Honma ${ }^{2}$, Hideyuki Matsumoto ${ }^{3,4}$, Katsuto Otake², Atsushi Shono ${ }^{2}$ \\ ${ }^{1}$ Department of Applied Chemistry, Tokyo Denki University, Tokyo, Japan \\ ${ }^{2}$ Department of Industrial Chemistry, Faculty of Engineering, Tokyo University of Science, Tokyo, Japan \\ ${ }^{3}$ Renewable Energy Research Center, Department of Energy and Environment, Advanced Industrial Science and Technology, \\ Koriyama, Japan \\ ${ }^{4}$ Department of Chemical Science and Engineering, Tokyo Institute of Technology, Tokyo, Japan \\ Email: kobayashi@mail.dendai.ac.jp
}

How to cite this paper: Kobayashi, D., Honma, C., Matsumoto, H., Otake, K. and Shono, A. (2018) Comparison of Threshold Power between Methylene Blue Degradation and KI Oxidation Reaction Using Ultrasound. Open Journal of Acoustics, 8, 61-69.

https://doi.org/10.4236/oja.2018.84006

Received: October 19, 2018

Accepted: December 24, 2018

Published: December 27, 2018

Copyright $\odot 2018$ by author(s) and Scientific Research Publishing Inc. This work is licensed under the Creative Commons Attribution International License (CC BY 4.0).

http://creativecommons.org/licenses/by/4.0/

\begin{abstract}
Ultrasound is used in various chemical reaction processes, and these reactions are influenced by ultrasonic frequency. A threshold power is required for the ultrasonic degradation reaction and oxidation reaction caused by hydroxyl radicals, and the cavitation threshold power is also influenced by frequency generally. In this study, the effects of frequency on the threshold power of methylene blue degradation and KI oxidation were investigated in the range between $22.8 \mathrm{kHz}$ and $1640 \mathrm{kHz}$. The threshold power of KI oxidation reaction increased with increasing frequency. This phenomenon well agrees with previous study, and it is revealed that the generation of $\mathrm{I}_{3}^{-}$ion is caused by oxidation reaction of $\mathrm{I}^{-}$ions with hydroxyl radicals. On the other hand, the threshold power of methylene blue degradation reaction was not affected by frequency. The ultrasonic degradation of methylene blue is considered to be caused by hydroxyl radicals, and there is a linear relationship between degradation rate constant and sonochemical efficiency value. However, it is guessed that the degradation of methylene blue is occurred inside cavitation bubble by pyrolysis at high frequency regions.
\end{abstract}

\section{Keywords}

Degradation, Methylene Blue Degradation, KI Oxidation, Frequency, Threshold Power

\section{Introduction}

Recently, ultrasound is used in various applications, and a frequency between 20 
$\mathrm{kHz}$ and $2 \mathrm{MHz}$ is mainly used in chemical reaction process such as synthesis of fine particles and decomposition of hazardous organic compounds [1]. The efficiency and rate of reaction in an ultrasonic field are influenced by frequency. In general, the maximum sonochemical effect caused by a cavitation has been observed around $300 \mathrm{kHz}$ [2]-[17], and sonochemical efficiency value $\left(S E_{\mathrm{KI}}\right)$ has been proposed [18]. $S E_{\mathrm{KI}}$ is often useful for evaluating the effect of frequency on sonochemical reaction rate quantitatively.

In our previous study, the effects of frequency on ultrasonic degradation of methylene blue as a model hazardous organic compound have been investigated, and a simple model for estimating the apparent degradation rate constant using $S E_{\mathrm{KI}}$ value, ultrasonic power, initial concentration, and sample solution volume is proposed [14] [15] [16]. Moreover, it is observed that a threshold power is required for degradation reaction to progress, and frequency has less influence on threshold power for degradation reaction of methylene blue. In general, cavitation threshold power is influenced by frequency, because the ultrasonic frequency is increased so the rarefaction phase shortens and it is necessary to increase the ultrasonic power to maintain an equivalent amount of cavitational energy in the system [1]. The cavitation threshold power has been investigated by observable secondary effects, such as microstreaming [19], free radical generation [20], and so on. For example, ten times more ultrasonic power is required to make water cavitate at $400 \mathrm{kHz}$ than at $10 \mathrm{kHz}$. On the other hand, the results of our previous study do not agree with conventional phenomenon. However, the effects of frequency and reactant on threshold power have not been investigated well.

In this study, the ultrasonic degradation reaction of methylene blue and ultrasonic oxidation reaction of KI were carried out, and the effects of ultrasonic frequency and power on degradation rate constant of methylene blue and generation rate of $\mathrm{I}_{3}^{-}$ion were examined. In addition, the effects of frequency on the threshold power of methylene blue degradation reaction and KI oxidation reaction were compared, and the effects of ultrasound on these two reactions were investigated.

\section{Experimental Procedure}

\subsection{Methylene Blue Degradation Reaction}

Figure 1 shows the complete experimental apparatus. A stainless steel vibration plate with an attached PZT transducer (Honda Electronics Co., Ltd.) was installed in the center of a bath at its bottom. The diameter of the vibration plate was $100 \mathrm{~mm}$; the diameters of 22.8 and $127 \mathrm{kHz}$ transducers were $45 \mathrm{~mm}$ each, whereas those of 490, 940, and $1640 \mathrm{kHz}$ transducers were $50 \mathrm{~mm}$ each. The transducers were driven by a power amplifier (1040L, E\&I), which in turn was driven by a continuous sinusoidal wave produced using a signal generator (WF1974, NF Corp.). The effective electric power input to the transducer was calculated from the voltage at both ends of the transducer, and the current was 


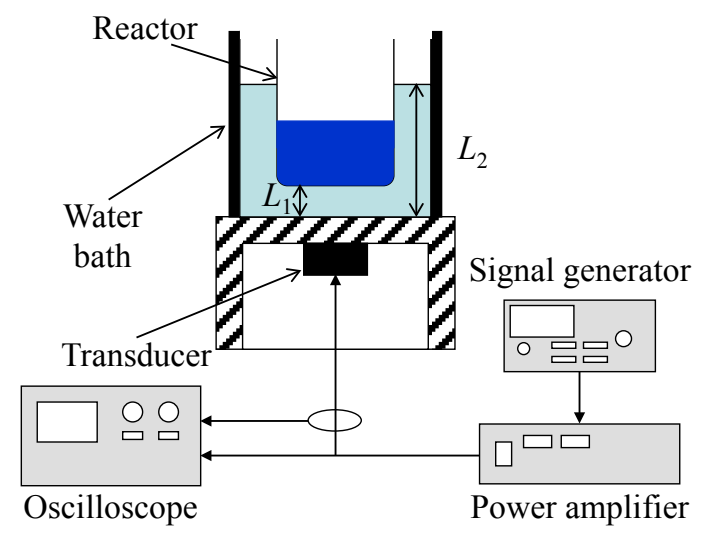

Figure 1. The experimental apparatus.

measured using both an oscilloscope (TDS3012C, Tektronix Inc.) and a current probe (TCP202, Tektronix Inc.). A glass reactor with variable vertical position was located in the center of the vibration plate. The diameter and approximate volume of the reactor were $85 \mathrm{~mm}$ and $10^{-3} \mathrm{~m}^{3}$, respectively. The temperature of the ultrasonic bath was maintained constant by circulating thermostat water.

Table 1 shows the experimental conditions for methylene blue degradation. Process variables were defined as follows: the ultrasonic frequency $(f)$, ultrasound output power $(P)$, initial methylene blue concentration $\left(C_{0, \mathrm{MB}}\right)$, distance between the ultrasonic transducer and bottom of the reactor $\left(L_{1}\right)$, distance between the ultrasonic transducer and level of the water bath $\left(L_{2}\right)$, and irradiation time $(t)$. The volume of the sample solution $(V)$ and temperature of the water bath $(T)$ were maintained constant. Before ultrasonic irradiation, the sample solution and remaining space in the reactor were deoxygenated with a nitrogen gas flow for $20 \mathrm{~min}$ at $298 \mathrm{~K}$. After de-oxygenation, the sample was irradiated with ultrasound under a continuous nitrogen gas flow $(0.1 \mathrm{~L} / \mathrm{min})$. The wavelength of ultrasound depended on ultrasonic frequency, and reaction field is influenced by irradiation distance. Therefore, the reaction was carried out at the optimum condition for various frequencies. Moreover, the temperature of water bath increased by ultrasonic irradiation. Thus, the temperature of the water bath was maintained by circulation of thermostatic water.

\subsection{KI Oxidation Reaction}

The experiment was carried out using the same apparatus as methylene blue degradation reaction. Table 2 shows experimental conditions for KI oxidation. The initial KI concentration was defined as $C_{0, \mathrm{KI}}$, and other process variables were the same as the above mentioned methylene blue degradation reaction.

\subsection{Analysis}

After ultrasonic irradiation, the methylene blue concentration $\left(C_{\mathrm{MB}}\right)$ was determined by measuring absorbance of the sample at a wavelength of $665 \mathrm{~nm}$ using a UV-Vis spectrometer (Agilent 8453, Agilent Technologies). The measured 
Table 1. The experimental conditions of methylene blue degradation.

\begin{tabular}{cccccccc}
\hline Frequency & $\begin{array}{c}\text { Ultrasonic } \\
\text { power }\end{array}$ & \multicolumn{2}{c}{$\begin{array}{c}\text { Reactor's } \\
\text { position }\end{array}$} & Temperature & $\begin{array}{c}\text { Initial } \\
\text { concentration of } \\
\text { methylene blue }\end{array}$ & $\begin{array}{c}\text { Irradiation } \\
\text { time }\end{array}$ & $\begin{array}{c}\text { Sample } \\
\text { volume }\end{array}$ \\
\hline$f$ & $P$ & $L_{1}$ & $L_{2}$ & $T$ & $C_{0, \mathrm{MB}}$ & $t$ & $V$ \\
\hline$[\mathrm{kHz}]$ & {$[\mathrm{W}]$} & {$[\mathrm{mm}]$} & {$[\mathrm{mm}]$} & {$[\mathrm{K}]$} & {$[\mathrm{mol} / \mathrm{L}]$} & {$[\mathrm{min}]$} & {$[\mathrm{L}]$} \\
\hline 22.8 & & 45 & 80 & & & & \\
127 & & 10 & 60 & & & & \\
490 & $0-20$ & 10 & 60 & 298 & 0.00001 & $0-60$ & 0.1 \\
940 & & 10 & 60 & & & & \\
1640 & & 10 & 60 & & & & \\
\hline
\end{tabular}

Table 2. The experimental conditions of KI oxidation.

\begin{tabular}{cccccccc}
\hline Frequency & $\begin{array}{c}\text { Ultrasonic } \\
\text { power }\end{array}$ & \multicolumn{2}{c}{$\begin{array}{c}\text { Reactor's } \\
\text { position }\end{array}$} & Temperature & $\begin{array}{c}\text { Initial } \\
\text { concentration } \\
\text { of KI }\end{array}$ & $\begin{array}{c}\text { Irradiation } \\
\text { time }\end{array}$ & $\begin{array}{c}\text { Sample } \\
\text { volume }\end{array}$ \\
\hline$f$ & $P$ & $L_{1}$ & $L_{2}$ & $T$ & $C_{0, \mathrm{KI}}$ & $t$ & $V$ \\
\hline$[\mathrm{kHz}]$ & {$[\mathrm{W}]$} & {$[\mathrm{mm}]$} & {$[\mathrm{mm}]$} & {$[\mathrm{K}]$} & {$[\mathrm{mol} / \mathrm{L}]$} & {$[\mathrm{min}]$} & {$[\mathrm{L}]$} \\
\hline 127 & & 10 & 60 & & & & \\
490 & $0-20$ & 10 & 60 & 298 & 0.1 & $0-30$ & 0.1 \\
1640 & & 10 & 60 & & & & \\
\hline
\end{tabular}

absorbance was converted to a concentration value using a standard curve for methylene blue.

The concentration of $\mathrm{I}_{3}^{-}$ion, which was generated by oxidation reaction of $\mathrm{I}^{-}$ ion, was also analyzed by measuring absorbance of the sample at a wavelength of $355 \mathrm{~nm}$ using a UV-V is spectrometer $(\varepsilon=26303 \mathrm{~L} / \mathrm{mol} \mathrm{cm})$.

The ultrasonic power level in the reactor was measured by a calorimeter [21]. Equation (1) gives the calculated ultra-sonic output power $(P)$.

$$
P=(d T / d t) \times c_{p} \times M
$$

Here, $c_{p}$ was the heat capacity of water, $M$ was the mass of water, $T$ was the temperature of the sample solution, and $t$ was the ultrasonic irradiation time. Ion exchanged water was used as the sample solution (volume, $0.1 \mathrm{~L}$ ).

\section{Results and Discussion}

\subsection{Effect of Ultrasonic Irradiation Conditions on Methylene Blue Degradation}

From the results of our previous study, the apparent rate constant of ultrasonic degradation of methylene blue was evaluated using a pseudo-first-order reaction model [14] [15] [16]. Figure 2 shows the effect of ultrasonic power on the apparent degradation rate constant in the range of frequency of $22.8 \mathrm{kHz}$ and 1640 


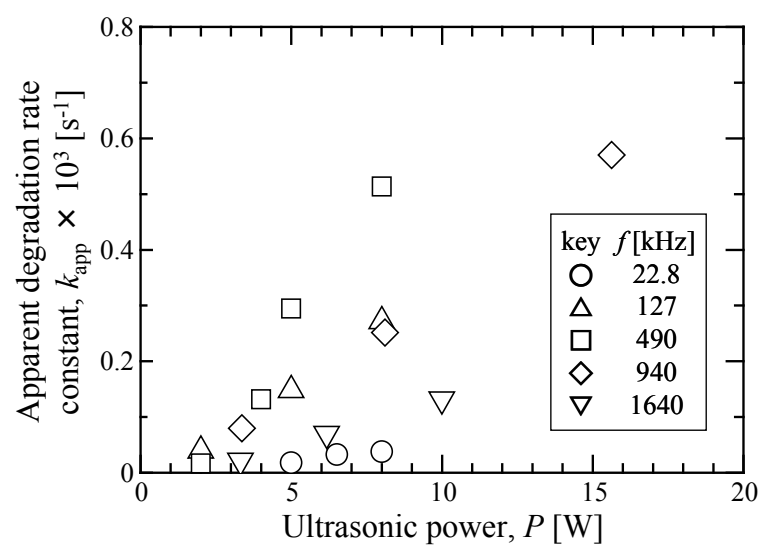

Figure 2. The effect of ultrasonic power on apparent degradation rate constant of methylene blue for various frequencies [15].

$\mathrm{kHz}$ [15]. The effects of frequency on degradation rate constant have been discussed in our previous studies [14] [15] [16]. It is also observed that the degradation rate constant increases with ultrasonic power, and there is a linear relationship between degradation rate constant and power at every frequency (22.8 $\mathrm{kHz}, 127 \mathrm{kHz}, 490 \mathrm{kHz}, 940 \mathrm{kHz}$, and $1640 \mathrm{kHz}$ ). Henglein and Gutierrez have investigated the sonication of aqueous $\mathrm{KI}$, and reported that the initial response of iodine yield appears to proportional to power, but this effect is reduced beyond $40 \mathrm{~W}$ and drops dramatically above $100 \mathrm{~W}$ [22]. The degradation rate constant appears to proportional to power, because the ultrasonic power in this study is less than $20 \mathrm{~W}$. In addition, a threshold power is existed for degradation reaction to progress, and it is found that the threshold power is not affected by ultrasonic frequency.

\subsection{Effect of Ultrasonic Irradiation Conditions on KI Oxidation}

When ultrasound was irradiated into an aqueous KI solution, $\mathrm{I}^{-}$ions were oxidized to give $\mathrm{I}_{2}$. When excess $\mathrm{I}^{-}$ions were present in solutions, $\mathrm{I}_{2}$ reacts with the excess $\mathrm{I}^{-}$ion to form $\mathrm{I}_{3}^{-}$ion. Figure 3 shows the effect of ultra-sonic power on the generation rate of $\mathrm{I}_{3}^{-}$ion at the frequencies of 127,490 , and $1640 \mathrm{kHz}$. The generation rate of $\mathrm{I}_{3}^{-}$ion was influenced by ultrasonic frequency, and the generation rate at 127 and $490 \mathrm{kHz}$ was higher than that at $1640 \mathrm{kHz}$. These phenomena also agree with previous reported results [18]. It is also observed that the generation rate increases with ultrasonic power, and there is a linear relationship between generation rate and power at every frequency. Moreover, a threshold power is also existed for oxidation reaction to progress, and it is found that the threshold power is affected by ultrasonic frequency.

\subsection{Effect of Frequency on Threshold Power}

Figure 4 shows the effect of ultrasonic frequency on the threshold power of methylene blue degradation and KI oxidation reaction. In the KI oxidation reaction 


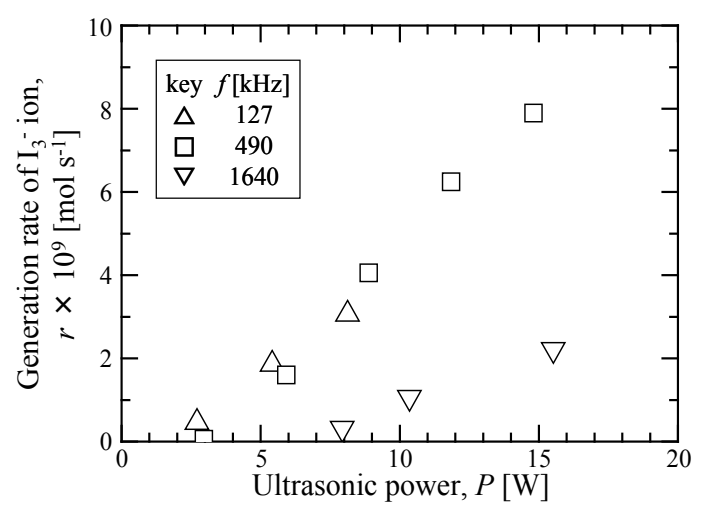

Figure 3. The effect of ultrasonic power on generation rate of $\mathrm{I}_{3}^{-}$ion for various frequencies.

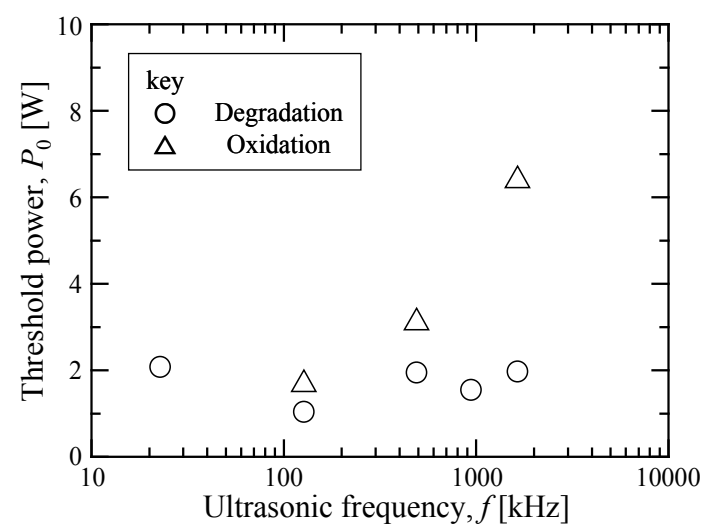

Figure 4. The effect of ultrasonic frequency on threshold power of methylene blue degradation and KI oxidation reaction.

process, the ultrasonic frequency affects the threshold power, and the threshold power increases with increasing frequency. This phenomenon well agrees with previous study [1]. Thus, it is clarified that the generation of $\mathrm{I}_{3}^{-}$ion was caused by oxidation reaction of $\mathrm{I}^{-}$ions with hydroxyl radicals.

On the other hand, in the methylene blue degradation reaction process, it is observed that the threshold power is not affected by frequency, and the threshold power is almost same value in every frequency, and it is about $2 \mathrm{~W}$. When the frequency is lower than $130 \mathrm{kHz}$, the values of threshold power of KI oxidation reaction and methylene blue degradation reaction are almost same. However, when the frequency is higher than $500 \mathrm{kHz}$, the value of threshold power of $\mathrm{KI}$ oxidation is higher than that of methylene blue degradation, and the difference becomes large with increasing frequency. In our previous study, there is a relationship between $S E_{\mathrm{KI}}$ value and degradation rate constant of methylene blue [14] [15] [16]. In addition, it has been reported that the ultrasonic degradation of methylene blue is enhanced by $\mathrm{TiO}_{2}$ particle addition under dark condition [23] [24] [25], and the presence of $\mathrm{TiO}_{2}$ particle accelerates the generation of hydroxyl radicals during ultrasonic irradiation even in the absence of UV irradi- 
ation [26]. Moreover, it has been also reported that the ultrasound and $\mathrm{TiO}_{2}$ particle exhibit synergistic effects in the degradation of azo dye of acid orange 8, and the origin of the synergistic effect is considered to be the formation of additional hydroxyl radicals by $\mathrm{TiO}_{2}$ particle from the extra hydrogen peroxide produced by ultrasound [27]. From the results of these studies, it is suggested that the degradation of methylene blue by ultrasound is caused by hydroxyl radicals, and the threshold power in the ultrasonic degradation of methylene blue increases with increasing frequency. However, the threshold power did not increase with increasing frequency. Therefore, it is guessed that the mechanism of degradation of methylene blue changes with frequency. When the frequency is lower than $130 \mathrm{kHz}$, the degradation of methylene blue is mainly occurred around cavitation bubbles by hydroxyl radicals. On the other hand, when the frequency is higher than $500 \mathrm{kHz}$, it is guessed that the degradation of methylene blue is occurred inside cavitation bubble by pyrolysis. However, this hypothesis has not been clarified yet. It is necessary to divide the degradation mechanism into hydroxyl radical decomposition and pyrolysis. Therefore, the effect of radical scavenger addition on the ultrasonic degradation of methylene blue will be investigated for various frequencies in the future.

\section{Conclusion}

The ultrasonic degradation reaction of methylene blue and ultrasonic oxidation reaction of KI were carried out by various frequencies in the range between 22.8 $\mathrm{kHz}$ and $1640 \mathrm{kHz}$. The threshold power was required for both degradation reaction and oxidation reaction. The threshold power of KI oxidation reaction increased with increasing frequency, and the threshold power of methylene blue degradation reaction was not affected by frequency. The mechanism of KI reaction was the oxidation reaction of $\mathrm{I}^{-}$ions with hydroxyl radicals. The degradation of methylene blue was also caused by hydroxyl radicals. However, the degradation of methylene blue was occurred inside cavitation bubbles by pyrolysis, when the frequency was higher than $500 \mathrm{kHz}$.

\section{Conflicts of Interest}

The authors declare no conflicts of interest regarding the publication of this paper.

\section{References}

[1] Mason, T.J. (2000) Sonochemistry. Oxford University Press, Oxford.

[2] Pétrier, C., Jeunet, A., Luche, J.-L. and Reverdy, G. (1992) Unexpected Frequency Effects on the Rate Oxidative Processes Induced by Ultrasound. Journal of American Chemical Society, 114, 3148-3150. https://doi.org/10.1021/ja00034a077

[3] Entezari, M.H. and Kruus, P. (1994) Effect of Frequency on Sonochemical Reactions. I: Oxidation of Iodide. Ultrasonics Sonochemistry, 1, S75-S79. https://doi.org/10.1016/1350-4177(94)90001-9

[4] Pétrier, C., Lamy, M.-F., Francony, A., Benahcene, A. and David, B. (1994) Sono- 
chemical Degradation of Phenol in Dilute Aqueous Solutions: Comparison of the Reaction Rates at 20 and $487 \mathrm{kHz}$. The Journal of Physical Chemistry, 98, 10514-10520. https://doi.org/10.1021/j100092a021

[5] Pétrier, C. and Francony, A. (1997) Ultrasonic Waste-Water Treatment: Incidence of Ultrasonic Frequency on the Rate of Phenol and Carbon Tetrachloride Degradation. Ultrasonics Sonochemistry, 4, 295-300. https://doi.org/10.1016/S1350-4177(97)00036-9

[6] Mark, G., Tauber, A., Laupert, R., Schuchmann, H.-P., Schulz, D., Mues, A. and von Sonntag, C. (1998) OH-Radical Formation by Ultrasound in Aqueous Solution-Part II: Terephthalate and Fricke Dosimetry and the Influence of Various Conditions on the Sonolytic Yield. Ultrasonics Sonochemistry, 5, 41-52. https://doi.org/10.1016/S1350-4177(98)00012-1

[7] Kojima, Y., Koda, S. and Nomura, H. (2001) Effect of Ultrasonic Frequency on Polymerization of Styrene under Sonication. Ultrasonics Sonochemistry, 8, 75-79. https://doi.org/10.1016/S1350-4177(00)00064-X

[8] Beckett, M.A. and Hua, I. (2001) Impact of Ultrasonic Frequency on Aqueous Sonoluminescence and Sonochemistry. The Journal of Physical Chemistry A, 105, 3796-3802. https://doi.org/10.1021/jp003226x

[9] Lesko, T., Colussi, A.J. and Hoffmann, M.R. (2006) Sonochemical Decomposition of Phenol: Evidence for a Synergistic Effect of Ozone and Ultrasound for the Elimination of Total Organic Carbon from Water. Environmental Science and Technology, 40, 6818-6823. https://doi.org/10.1021/es052558i

[10] Asakura, Y., Nishida, T., Matsuoka, T. and Koda, S. (2008) Effects of Ultrasonic Frequency and Liquid Height on Sonochemical Efficiency of Large-Scale Sonochemical Reactors. Ultrasonics Sonochemistry, 15, 244-250. https://doi.org/10.1016/j.ultsonch.2007.03.012

[11] Sáez, V., Esclapez, M.D., Bonete, P., Walton, D.J., Rehorek, A., Louisnard, O. and González-Garcia, J. (2011) Sonochemical Degradation of Perchloroethylene: The Influence of Ultrasonic Variables, and the Identification of Products. Ultrasonics Sonochemistry, 18, 104-113. https://doi.org/10.1016/j.ultsonch.2010.03.009

[12] Son, Y., Lim, M., Khim, J., Kim, L.-H. and Ashokkumar, M. (2012) Comparison of Calorimetric Energy and Cavitation Energy for the Removal of Bisphenol-A: The Effects of Frequency and Liquid Height. Chemical Engineering Journal, 183, 39-45. https://doi.org/10.1016/j.cej.2011.12.016

[13] Park, B., Cho, E., Park, H. and Khim, J. (2011) Sonophotocatalytic Destruction of Chloroform: Comparison of Processes and Synergistic Effects. Japanese Journal of Applied Physics, 50, 07HE10. https://doi.org/10.1143/JJAP.50.07HE10

[14] Kobayashi, D., Honma, C., Suzuki, A., Takahashi, T., Matsumoto, H., Kuroda, C., Otake, K. and Shono, A. (2012) Comparison of Ultrasonic Degradation Rates Constants of Methylene Blue at $22.8 \mathrm{kHz}, 127 \mathrm{kHz}$, and $490 \mathrm{kHz}$. Ultrasonics Sonochemistry, 19, 745-749. https://doi.org/10.1016/j.ultsonch.2012.01.004

[15] Kobayashi, D., Honma, C., Matsumoto, H., Takahashi, T., Kuroda, C., Otake, K. and Shono, A. (2014) Kinetics Analysis for Development of a Rate Constant Estimation Model for Ultrasonic Degradation Reaction of Methylene Blue. Ultrasonics Sonochemistry, 21, 1489-1495. https://doi.org/10.1016/j.ultsonch.2013.12.022

[16] Kobayashi, D., Honma, C., Matsumoto, H., Takahashi, T., Shimada, Y., Kuroda, C., Otake, K. and Shono, A. (2014) Effect of Ultrasonic Frequency and Initial Concentration on Degradation of Methylene Blue. Japanese Journal of Applied Physics, 53, 07KE03. https://doi.org/10.7567/JJAP.53.07KE03 
[17] Dolores, R., Raquel, S. and Adianez, G.-L. (2015) Sonochemical Synthesis of Iron Oxide Nanoparticles Loaded with Folate and Cisplatin: Effect of Ultrasonic Frequency. Ultrasonics Sonochemistry, 23, 391-398. https://doi.org/10.1016/j.ultsonch.2014.08.005

[18] Koda, S., Kimura, T., Kondo, T. and Mitome, H. (2003) A Standard Method to Calibrate Sonochemical Efficiency of an Individual Reaction System. Ultrasonics Sonochemistry, 10, 149-156. https://doi.org/10.1016/S1350-4177(03)00084-1

[19] Elder, S.A. (1959) Cavitation Microstreaming. The Journal of Acoustical Society of America, 31, 54-64. https://doi.org/10.1121/1.1907611

[20] Carmichael, A.J., Mossoba, M.M., Riesz, P. and Christman, C.L. (1986) Free Radical Production in Aqueous Solutions Exposed to Simulated Ultrasonic Diagnostic Conditions. IEEE Transactions on Ultrasonics, Ferroelectrics and Frequency Control, 33, 148-155. https://doi.org/10.1109/T-UFFC.1986.26807

[21] Contamine, R.F., Wilhelm, A.M., Berlan, J. and Delmas, H. (1995) Power Measurement in Sonochemistry. Ultrasonics Sonochemistry, 2, S43-S47. https://doi.org/10.1016/1350-4177(94)00010-P

[22] Henglein, A. and Gutierrez, M. (1990) Chemical Effects of Continuous and Pulsed Ultrasound: A Comparative Study of Polymer Degradation and Iodide Oxidation. The Journal of Physical Chemistry, 94, 5169-5172. https://doi.org/10.1021/j100375a073

[23] Kobayashi, D., Shimakage, K., Honma, C., Matsumoto, H., Otake, K. and Shono, A. (2015) Effect of Particle Addition on Ultrasonic Degradation Reaction Rate. Open Journal of Acoustics, 5, 67-72. https://doi.org/10.4236/oja.2015.53006

[24] Honma, C., Kobayashi, D., Matsumoto, H., Takahashi, T., Kuroda, C., Otake, K. and Shono, A. (2013) Effect of Particle Addition on Degradation Rate of Methylene Blue in an Ultrasonic Field. Japanese Journal of Applied Physics, 52, 07HE11. https://doi.org/10.7567/JJAP.52.07HE11

[25] Shimizu, N., Ogino, C., Dadjour, M.F. and Murata, T. (2007) Sonocatalytic Degradation of Methylene Blue with $\mathrm{TiO}_{2}$ Pellets in Water. Ultrasonics Sonochemistry, 14, 184-190. https://doi.org/10.1016/j.ultsonch.2006.04.002

[26] Shimizu, N., Ogino, C., Dadjour, M.F., Ninomiya, K., Fujihira, A. and Sakiyama, K. (2008) Sonocatalytic Facilitation of Hydroxyl Radical Generation in the Presence of $\mathrm{TiO}_{2}$. Ultrasonics Sonochemistry, 15, 988-994. https://doi.org/10.1016/j.ultsonch.2008.04.011

[27] Selli, E. (2002) Synergistic Effects of Sonolysis Combined with Photocatalysis in the Degradation of an Azo Dye. Physical Chemistry Chemical Physics, 4, 6123-6128. https://doi.org/10.1039/b205881b 